\title{
AIDS in Haiti: Situating the Incidence and Prevalence of AIDS in Structural Violence Samra Hasnain
}

Samra Hasnain is in her final year at the University of Toronto, pursuing an undergraduate degree in Human Biology and Caribbean Studies. She is particularly interested in examining the structural forces that shape patterns of health and disease in the Caribbean and the ways in which these patterns illuminate the deeper rooted inequalities that exist globally.

\section{Introduction}

In light of the past decade of rising popular interest and alarm towards infectious epidemic diseases, there has been a surge of movement throughout developed nations in allocating funds towards research and action programs to respond to these concerns. However, while the popularization of the concept of "emerging infectious diseases" has fuelled a sense of urgency towards developing ways to curb the rise and the spread of disease, it also illuminates the inequalities that exist globally in the distribution and outcome of infectious diseases. Large-scale social forces, such as political violence, poverty, racism, sexism, gender and other social inequalities, rooted in historical and economic processes, shape the distribution and outcome of infectious diseases such as HIV/AIDS and TB. These social forces, coined as "structural violence" by Paul Farmer (2001), create spaces of vulnerability by firstly shaping the risk of infection and then the outcome by determining who has access to diagnostics and effective therapy following infection. Drugs that could stop or slow down these epidemics, such as first- and second-line antiretrovirals, are not available in the places where populations are most vulnerable and where these diseases take their highest toll. (Farmer 37-44).

Amidst these infectious diseases, the AIDS epidemic serves as perhaps the best model for addressing the inequalities that exist in the distribution and outcome of disease. Emerging from its initial epicenters (America, Europe and Africa) in the early 1980's, AIDS has followed the trail of human interactions to become a global issue (Kreniske 33). It differs from other infectious diseases in the sense 
that it is transmitted without an intervening vector; human beings serve as the only carriers for the virus. HIV is most commonly transmitted in three ways; during sexual contact with an infected individual that results in coming into contact with bodily fluids (semen and vaginal fluids), exchanging blood with infected individuals (injection-drug use and blood transfusions) and via vertical transmission (perinatal exchange of fluids between mother and child - transplacental exchange vaginally at the time of birth and through breast milk). As a result, HIV strikes human populations at the very process of biological and social reproduction.

Another important aspect to note is that the experience of contracting HIV infections in the developing and developed nations has been different from the onset of the pandemic. The appearance of HIV/AIDS in the global south did not receive the immediate attention and prominence it assumed in the United States and Europe. AIDS was just added to the list of the many deadly epidemic diseases that were already present (Kreniske, 33). This uneven impact of AIDS has matched the uneven distribution and spread of the virus. The differences behind these uneven distributions have arisen not from inherent biological differences between individual and groups, but rather from differences in patterns of behavior within populations in response to socio-economic and cultural determinants. This illustrates that the AIDS pandemic cannot be viewed as a single phenomenon for which there is a simple global solution. Instead, different neighbourhoods, cities, regions, and countries require different intervening strategies to curb the prevalence and spread of HIV (Lindenbaum, 192-193).

Globally, among these developing nations, the Caribbean stands out as being the second-most affected region in the world (coming second to sub-Saharan Africa) with the Bahamas and Haiti having the highest prevalence rates of HIV infection in the region respectively. As a result, the study of the AIDS epidemic in a Caribbean context allows the opportunity to gain an understanding on the socio-cultural dimensions of disease. With a focus of situating the analysis in Haiti, this paper aims to investigate the social forces that have contributed to the generalized AIDS epidemic that exists within this nation at present. While there are numerous issues (such as the consequence of political instability, income inequality, land reform, the alienation of peasants from the land, labor migration, colonial and post-colonial patterns of industrial exploitation, the resulting proliferation of informal settlements (shanty towns), 
gender hierarchies, and the traditional and emerging patterns of sexual union) that have caused Haiti to become a vulnerable space for the spread of HIV, this paper will focus specifically on the political, economic and gender dimensions of structural violence in Haiti. In doing so, the aim of this paper is to analyze the link between structural violence and AIDS and address how these specific social forces have shaped the incidence and the prevalence of AIDS in Haiti.

\section{Conceptualizing the Vulnerability of the Haitian State: Situating Political and Economic Instability in Historical Processes}

To gain an understanding of the reasons behind the high prevalence rate of HIV infections in Haiti, it is essential to look at the factors that have caused the country to become vulnerable space to begin with. Like much of the Caribbean, Haiti's vulnerability is rooted deeply within colonialism. The Spanish first arrived to the island they later named as Hispaniola in 1493 and subsequently for the next 125 years fought against other European powers for control. The French West India Company eventually established control over a third of the colony and named it Saint- Domingue. These French colonialists sought to make the colony profitable and established a large-scale farming system (plantation system) that required a large labor force (Farmer 1993:153-160). As a result, by the end of the17 century, African slavery was instituted to obtain labor to work on plantation crops of sugar and coffee for export. The plantation economy reached staggering proportions as the demand for these luxury products increased so much so that by the end of the 18th century, the colony's enslaved Africans were producing $40 \%$ of all the sugar and $60 \%$ of all the coffee consumed in Europe. Needless to say, Saint- Domingue undeniably became one of the wealthiest colonies in the Caribbean (Oliver- Smith 33).

Hierarchies of class, race and gender were inherent to plantation societies as they served to regulate the slave populations and to justify the authority of the European plantocracy. These boundaries were complicated when European planters fathered illegitimate offspring through the sexual exploitation of their enslaved population. The French colonial system often defined these individuals as free and able to inherit property and own slaves. These "mulattoes" added another dimension to the social hierarchies of the 
plantation societies and would eventually resemble some of Haiti's first national elites (Oliver- Smith 34).

In 1789 , the revolutionary fervor in France spread to these early elite classes consisting of free people of color in SaintDomingue, initiating a series of reform and resistance movements in 1790 that progressed into full-scale slave revolts and ultimately culminated in the colony's independence in 1804. Haiti became the first independent nation in the Caribbean and Latin America. More importantly, Haiti became the world's first black republic (Farmer 1993:164-165).

Since gaining independence in 1804, Haiti has been severely punished by the international community. It began immediately after independence with France refusing to recognize the new republic and demanding that reparations be paid for the loss of "property," (slaves and land) in the amount of 150 million gold francs (which translates to $\$ 21$ billion). France threatened Haiti with invasion and simultaneously placed an embargo along with Britain and the United States to pressure Haiti into accepting its demands. In 1825, due to this intense international pressure, Haiti agreed to pay the reparation (Oliver-Smith 33-35).

At this moment a question that is necessary to addresses is, "Why might a country of former slaves feel compelled to remunerate the plantocracy for losses incurred in a war of liberation?" (Farmer 1993:168). Putting aside the threat of invasion and the pressures put forth by the embargo, it is necessary to mention that the Haitian elite saw their own survival at stake in this issue of diplomatic recognition. The growth of the Haitian republic was held, by these elites, as being tied to continued export of subtropical commodities (Farmer 1993:168 - 170). As a result, while European and U.S. leaders began a campaign to isolate Haiti both politically and economically in the early $19^{\text {th }}$ century, the Haitian government and elites allowed these nations to extract Haitian resources (income largely from sugar, coffee, and indigo) to fulfill the debt obligations (Oliver-Smith 33). Thus while Haiti may have been diplomatically isolated, these political maneuvers did not include commercial isolation. The Haitian government and elites negotiated the extraction process with foreign powers, principally the United States, and began accumulating power and wealth while draining the nation's resources. This result was achieved through the use of 
brutality, militarism, mismanagement, and corruption that subsequently impoverished the rest of the population. Under the weight of the crippling debt and the embargo, Haiti went from being the richest Caribbean colony, "the pearl of the Antilles," to the most impoverished nation in the Western Hemisphere. Haitian elites did little to construct a viable infrastructure or a functional institutional framework in the country (Oliver-Smith 33-34).

During this period, Haiti experienced almost continuous foreign intervention by both the United States and European powers. The United States alone sent warships into Haitian waters twenty six times during the period of 1849 - 1914 under guise of wanting to protect the lives and the property of American citizens. In 1915, penetration of foreign capital coupled with the continuous invasion by U.S warships led to an armed occupation of Haiti by the United States Marine Corps. During this period of U.S. occupation in Haiti, between 1915-1934, the United States exerted enormous influence in Haiti. Unlike what is often suggested, the occupation was not the sudden manifestation of a new U.S. interest in protecting Haitians from their corrupt leaders. Rather, it was a continuation of the pattern of exploitation and domination (Farmer 1993:180-183).

Recent developments, in the last quarter of the $20^{\text {th }}$ century, have amplified Haiti's impoverishment and vulnerability. Following the brutal dictatorship of "Papa Doc" Duvalier, his son "Baby Doc" (Jean- Claude Duvalier) inherited the regime in 1971 and left the nation in even greater debt to foreign lenders due to the continual misappropriation of resources and even outright theft. The second Duvalier regime, a virtual kleptocracy, was supported by the United States and as such approved the catastrophic USAID-ordered slaughter of all of Haiti's pigs to limit the spread of African swine flu virus (Dupuy 50-51). The loss of the pig population, which was essentially the source of peasant savings, emergency capital, and nutrition, left the rural people in an even more impoverished and vulnerable state. In addition to this, rural Haitians were forced to cut to trees to produce charcoal, which led an almost complete deforestation of Haitian terrain (Oliver-Smith 35).

USAID programs along with the imposition of structural adjustment policies by the World Bank and IMF further weakened the rural economy. With a goal to develop Haiti's cities into centers of export production for U.S. companies, USAID, working with large landowners, encouraged the construction of agro-processing 
facilities, while IMF-imposed tariff reductions opened Haitian markets to subsidized U.S. rice surpluses, undercutting local production of the nation's staple crop and dismantling the rural economy (Dupuy 52-56). This resulted in a massive migration of the rural population to the cities where impoverished migrants took up residence in slums and shantytowns. The demand for jobs and services by the displaced rural populations quickly exceeded the supply, deepening the impoverishment of the extremely dense populations in cities. Political instability during the last 20 years has also led to high rates of unemployment as companies, having been forced to down size, have reduced the numbers of jobs available (Oliver-Smith 35).

Within this context, when the AIDS epidemic emerged in Haiti in the early 1980's, it surfaced during a period of massive and prolonged social upheaval. Political unrest undermined preventive efforts and may have helped, through other mechanisms, to spread HIV. Political disruptions have also served to paralyze coordinated efforts by the state to prevent HIV transmission. For example, while in 1991 the country's first democratically elected government (led by Jean-Bertrand Aristide) installed a new Ministry of Health which promised to make AIDS prevention its top priority however; its initiatives were disrupted when, in September of the same year, a violent military coup brought a swift end to Haiti's democratic government. The 1991 coup d'état not only halted the coordinated responses to the AIDS epidemic, it had a direct impact on the pattern of HIV transmission. Prior to the coup, urban population in places such as Cité Soleil had higher rates of seropositivity than rural populations. However following the coup, when the army targeted urban slums for brutal repression, large numbers of adult residents from these urban places fled to rural areas. This internal displacement substantially changed the equations describing the dynamics of HIV transmission within the country (Farmer 2001:144).

Since 1991, the office responsible with coordinating preventive programs has been further constrained by six coups d'état, which have led, inevitably, to personnel changes and to more significant disruptions. The result is there had been no comprehensive effort to prevent HIV transmission in Haiti. Even in Port-au-Prince, what has been accomplished thus far, in the way of spreading awareness of HIV transmission, has only reached a small segment of the population (for example, Haitians who are 
francophone, literate, and have access to televisions). These messages have been especially unsuccessful in rural areas, where the populations are most vulnerable at present (Farmer, 2001:145).

In addition to the failure of preventative programs, the lack of access to medical resources and services for the poor segment of the Haitian population has further entrenched AIDS within the society. Seeking medical help is challenging and costly for most of the population and for those who have been diagnosed with AIDS, antiretroviral are unaffordable and often unavailable (Farmer 2001:146). As a result, political instability within Haiti has structured both the transmission of HIV and also the nature of its outcomes once an individual is sick with complications of AIDS.

\section{Economic Dimension of AIDS}

As mentioned earlier, the social and political unrest in Haiti (specifically in the last two decades) has had a massive impact in further impoverishing the Haitian state. Poverty has played a major role in generating vulnerability towards HIV infections by limiting the types of opportunities that are available for those living in the region. Low income, high rates of unemployment and the lack of social welfare have and continue to serve as strong motivators for sex work. Entering into this industry has exposed the improvised segment of the population to HIV infection and has increased their overall risk of contracting the disease. What is important to emphasize is that it is not sex work specifically that increases vulnerability but rather the economic conditions alongside other social inequalities that have restricted individuals ability of choice, leaving them no alternatives but to engage in behaviour that increases their risk to HIV infection (Kreniske 37).

\section{Gender and Sexuality}

The fact that AIDS has been stigmatized globally as a homosexual disease (predominantly inflicting gay men) illustrates the need to examine the forces of gender and sexuality in relation to the epidemic. While the majority of infections in the developed world are among men, the complete opposite is seen in the developing world. Increasingly, HIV is predominantly infecting women as opposed to men via heterosexual sex in places such as the Caribbean (Kreniske 33-37). Due to the centrality of sexual behaviour to the 
AIDS epidemic, since HIV is primarily sexually transmitted within populations, the examination of how gender and sexuality affect risk taking in sexual behaviour, sustain vulnerabilities and undermine resilience in dealing with the epidemic need to be addressed (Kempadoo 179-181). In doing so the hope is to understand why women and young girls face infection rates several times higher than the general population.

As stated earlier, HIV in the Haiti, as well as the rest of the Caribbean, is primarily transmitted through heterosexual intercourse. Despite the initiatives taken by the Ministry of Public Heath to disseminate information about HIV transmission and prevention, rates of infection have continued to increase. As Kamala Kempadoo states, there seems to be a "disconnect" between knowledge about sexually transmitted infections such as HIV and sexual behaviour. This is the reason as to why HIV prevention and AIDS treatment activities have failed in the region. What this indicates is that to create effective prevention strategies, the factors that are preventing the application of knowledge in sexual behavior have to be examined. Undoubtedly, power relations between sexes and hegemonic constructions of gender that are present within Haitian society are critical to this issue (Kempadoo 182).

Within Haiti, a "risk" centered quantitative approach has been used to explain why certain groups within societies are more vulnerable to the AIDS epidemic than others. This concept of "risk" has come to be equated with individual behavioural risks, such as inconsistent condom use or multiple partners. Thus, HIV prevention has been focusing on an individualized view of sexuality and the physical act of unprotected sex has initially become the major focus for intervention aimed at behavioural modification. The assumption is that "high-risk" sexual behavior can be changed into safer sexual behavior by encouraging desired behaviors through the provision of knowledge. This approach, based on the biomedical model that focuses on individual behaviour change, makes the assumption of a rational individual who is motivated by self-protected and enjoys the freedom to choose exactly when, how and with whom to engage in sex. In such a scenario the risk that such an individual takes can be diminished through information and education. However, this model is deeply erroneous due to the fact that firstly it does not take into account that sexual behaviour is often driven by desire, which is deeply irrational. Secondly, this extremely narrow understanding of risk does not take into account the social inequities that exist 
between men and women that play a substantial role in increasing women's risk to HIV. Women's very position in society is the primary cause of exposure to risk of HIV infection in Haiti. Thus when prevention is focused on promoting condom use, faithfulness, partner reduction and abstinence, it fails to consider the reality of what it actually means for women to abstain, be faithful or use a condom. The fact is that these options do not take place in isolation; each of them exists and is lived in specific socio-cultural, economic and political context, which predispose, enable and/or reinforce behaviour and constrict free choice. Thus in Haiti, the traditional gendered cultural norms of power and sexuality make it difficult, sometimes even impossible, for women to act on these behavioural suggestions as viable options for prevention. Cultural norms of power, unequal gender relations, social expectations, desire and unequal access to economic and cultural resources render knowledge alone inadequate, especially among poor women (Kempadoo 182188).

Another aspect that has been disregarded in this approach has been the complexity of sexual relationships. These relationships are embodied in and are products of negotiated relationships to power, economic dependence and social inequality that contextualize, influence and in many ways determine sexual behaviour. In the majority of these relationships men hold the power and thus control the relationship and women are often left to negotiate their position. For example, the decision to use a condom is a decision to not reproduce at the same time as to prevent infection. It is also a decision that must be made for each act of intercourse. Thus women must repeatedly address the issue of sexual decision-making and sexual control and each time this is done they are emotionally, sexually, physically and economically vulnerable (McNamara 122-125).

What this example highlights is that to implement successful and culturally relevant policies to prevent HIV transmission, the larger social and gender inequalities and structural determinants of choices and behaviors that exist within Haiti in which risky practices occur have to be addressed. 


\section{Conclusion}

This paper has attempted to illustrate and examine how the political, economic and gender dimensions of structural violence have shaped the incidence and the prevalence of AIDS in Haiti. This has illustrated in a broader way the fundamental idea that disease and illness are not random phenomenon. Each society by its organization and core economic features, rooted in historical processes, produces certain characteristic patterns of disease and death that are specific to it. As a result the load of disease born by each society is one indicator of the political economy and the social life of the society. As Kreniske has articulated, "disease, then, is, in a large part, a social event expressing the central realities of the society in which it occurs" (35). Thus, by examining the social determinants of AIDS this paper has illustrated how vulnerability to HIV infection are not simply due to certain risk factors that have manifested due to risky behavioural practices but rather that these risky behavioural practices have been the result of unequal gender relations, social expectations, desire and unequal access to economic and cultural resources.

One dimension that this paper has not addressed is the impact of AIDS on the families of individuals that have been affected by the disease. Due to the fact that AIDS predominantly affects women within the Caribbean, how does the AIDS epidemic affect domestic arrangements and education of children? How are social units in the event of loss of personnel impacted? And lastly, how does AIDS affect social reproduction? These questions serve to emphasize that while analyzing the impact of AIDS on societies we need to remember that like any medical condition, AIDS affects individuals and that their experience is just as important. 


\section{Work Cited}

Dupuy, Alex. "Globalization, the World Bank and the Haitian Economy" in Contemporary Caribbean Cultures and Societies in a Global Context. UWI, 2005. 43-70. Print.

Farmer, E. Paul. Infections and Inequalities: The modern plagues. Los Angeles: University of California Press, 2001. Print.

Farmer, E. Paul. "AIDS and Accusation: Haiti, Haitians and the Geography of Blame" in AIDS and Culture: The Human Factor. Ed. D.Feldman. Berkley: University of California Press, 1993. 67-91. Print.

Kempadoo, Kamala. "Centering Praxis in Policies and Studies of Caribbean Sexuality" in Sexuality, Social Exclusion and Human Right. Ed. Christine Barrow, Marjan Be Bruin and Robert Carr. Kingston: Ian Randle Publishers, 2009. 179-190. Print.

Kreniske, John. "AIDS in the Dominican Republic: Anthropological Reflections on the Social Nature of Disease" in AIDS in Africa and the Caribbean. Ed. George C. Bond et al. Oxford: Westview Press, 1997. 3351. Print.

Lindenbaum, Shirley. "AIDS: Body, Mind and History" in AIDS in Africa and the Caribbean. Ed. George C. Bond et al. Oxford: Westview Press, 1997. 191-194. Print.

McNamara, Regina. "Female Genital Health and the Risk of HIV Transmission" in AIDS in Africa and the Caribbean. Ed. George C. Bond et al. Oxford: Westview Press, 1997. 115- 130. Print.

Oliver-Smith, Anthony. "Haiti and the Historical Constructions of Disasters" in NACLA Report on the Americas. 2010. 43.3: 32-36. Print. 